\title{
Environmental dichlorodiphenyltrichlorethane or hexachlorobenzene exposure and breast cancer: is there a risk?
}

\author{
Corinne Charlier ${ }^{1, *}$, Jean-Michel Foidart ${ }^{2}$, \\ François Pitance ${ }^{2}$, Philippe Herman ${ }^{2}$, Ulysse \\ Gaspard $^{2}$, Michel Meurisse ${ }^{3}$ and Guy \\ Plomteux ${ }^{1}$ \\ ${ }^{1}$ Clinical Toxicology Laboratory, \\ ${ }^{2}$ Gynaecology Department, \\ ${ }^{3}$ Endocrine Surgery Department, \\ Sart Tilman University Hospital, University of Liege, \\ Liege, Belgium
}

\begin{abstract}
The carcinogenic potential of environmental xenoestrogens (i.e., organochlorines) is a matter of controversy. Their pathogenic role as promoters in breast cancer has been previously suggested. In Europe, despite their prohibition since the '70s, residues persist in soil and rivers resulting in a widespread contamination of the general population. In this study, we have compared the serum levels of $p, p^{\prime}-1,1$-dichloro2, 2-bis (4-chlorophenyl) ethylene (DDE) and hexachlorobenzene (HCB) in 231 women at the time of breast cancer discovery and in 290 age-matched healthy controls. p, $p^{\prime}$-DDE was found in $76.2 \%$ of cases and in $71.1 \%$ of controls but HCB was present only in $12.6 \%$ of cases (29 from 231) and in $8.9 \%$ of controls (26 from 290). Even if taking all undetectable results (recorded as " 0 ") into consideration, mean values were significantly different in cases when compared to controls. The serum level of $p, p^{\prime}-D D E$ was $3.46 \pm 3.48 \mathrm{ppb}(0.58 \pm 0.58 \mu \mathrm{g} / \mathrm{g}$ lipid) in patients and $1.85 \pm 2.09 \mathrm{ppb}(0.31 \pm 0.35 \mu \mathrm{g} / \mathrm{g}$ lipid) in controls $(p<0.0001)$. The HCB serum level was $0.66 \pm 1.25 \mathrm{ppb}$ $(0.11 \pm 0.21 \mu \mathrm{g} / \mathrm{g}$ lipid) in patients and $0.20 \pm 1.02 \mathrm{ppb}$ $(0.03 \pm 0.17 \mu \mathrm{g} / \mathrm{g}$ lipid) in controls $(p<0.0001)$. When considering $p, p^{\prime}-D D E$ and $\mathrm{HCB}$ as binary variables (1 if higher than the limit of quantification, 0 if lower), the presence of both residues was significantly associated with an increased risk of breast cancer development (OR 2.21, 95\% Cl 1.41-3.48 for p, $p^{\prime}$-DDE and OR $4.99,95 \% \mathrm{Cl} 2.95-8.43$ for $\mathrm{HCB}$ ). No excess was observed among parous women or when familial history of breast cancer was considered. In the cancer group, no differences in serum levels of $p, p^{\prime}-D D E$ or HCB were found in relation with estrogen-receptor (ER) status, Bloom stage or lymph node metastasis, but the HCB level was moderately correlated with tumor size $(p=0.026)$.
\end{abstract}

\footnotetext{
*Corresponding author: Dr. Corinne Charlier, Laboratoire de Toxicologie clinique, CHU Sart Tilman, 4000 Liege, Belgium

Phone: +32-4-3668818, Fax: +32-4-3668889,

E-mail: C.Chalier@chu.ulg.ac.be
}

Keywords: breast cancer; endocrine disruptors; organochlorine pesticides.

\section{Introduction}

Breast cancer is the most common cancer in women, affecting one out of 10 women in Europe and the USA. Its etiology and metastasizing ability are multifactorial, including: genetic predisposition, association of multiple risk factors (alcohol, nulliparity, etc.), and hormonal implication (endogenous or exogenous hormones, or metabolism-derived products) during the process of carcinogenesis but also during the propagation of tumors (1). Hormones, particularly estrogen plus progestin, have been shown to increase breast cancer risk but not associated mortality $(2-5)$. It has been suggested that hormone replacement therapy (HRT)-associated breast cancers maintain an estrogen-receptor positivity $(E R+)$, a more benign course and a low rate of metastasis associated with a better survival (5).

The hormonal dependency of breast cancer fostered research on the potential pathogenic role of occupational and environmental exposure to endocrine-disrupting pesticides. This issue, however, remains controversial. Out of 29 published studies (for a review, see 6), 21 yielded negative results, and only five found a significant excess risk of breast cancer development, particularly in post-menopausal ER + breast cancer women (7). Therefore, it is uncertain how to interpret these contradictory findings. Moreover, in those studies, the percentage of ER+ cancers and of lymph node positivity and metastasis were not systematically evaluated nor correlated with the levels of organochlorine derivatives in blood.

We previously demonstrated that $67 \%$ of the general population was contaminated by $\mathrm{p}, \mathrm{p}^{\prime}-1,1$-dichloro-2, 2-bis (4-chlorophenyl) ethylene (DDE) and $14 \%$ by hexachlorobenzene (HCB) (8). The present casecontrol study was designed to compare women suffering from breast cancer to a control group and to assess the possible correlation between the presence of serum organochlorines and breast cancer incidence, ER positivity and lymph node metastasis.

\section{Materials and methods}

\section{Subjects}

The case-control study involved 231 women suffering from breast cancer and 290 controls, all Caucasian women attending the University Hospital in Liege during the period June 
2001-January 2002. Cases were evaluated at the time of surgery. Age-matched ( \pm 2 years) control subjects were selected at random in a population of presumably healthy women consulting for routine systematic cervico-vaginal cytological screening. For each subject, information regarding age at menarche, pregnancy (number of children), breast-feeding and duration of lactation, menopausal status and family history of breast cancer (mother, sister or grandmother) were recorded by interview. Post-menopausal women were asked for age at menopause and HRT use. Moreover, for breast cancer women, information concerning tumor size, ER status, stage of the disease (Bloom stage) and metastatic spread to axillary lymph nodes were obtained from laboratory and medical records. Metastasis in liver, bone, brain or lung was searched for using standard techniques.

All patients gave their informed consent for participating in the study. For controls, blood specimens were taken at the time of examination, whereas for women with breast cancer, samples were collected prior to surgery. Blood samples $(10 \mathrm{ml})$ were drawn in the early morning after overnight fasting and were immediately centrifuged with serum specimens kept frozen at $-18^{\circ} \mathrm{C}$ until assay (within 1 week).

\section{Methods}

We focused on o, $\mathrm{p}^{\prime}$-1,1-trichloro-2, 2-bis (4-chlorophenyl) ethane (DDT), p, $p^{\prime}-D D T, o, p^{\prime}-D D E, p, p^{\prime}-D D E$ and HCB, which were quantified simultaneously in serum using a gas chromatographic analyzer coupled to an ion-trap mass spectrometer detector (Saturn 2000, Varian, Harbor City, CA, USA). The analytical methodology is described and validated elsewhere (8). Briefly, sample preparation included a liquid-liquid extraction (petroleum ether: diethylether, 98:2) followed by a solid-phase extraction (Bond Elut Certify, Varian, Harbor City, CA, USA). The eluate was evaporated to dryness, reconstituted in $\mathrm{n}$-hexane and then injected into the gas chromatograph (Saturn 2000, Varian, Harbor City, CA, USA). The column (30 $\mathrm{m} \times 0.25 \mathrm{~mm}$ internal diameter) was an HP-5 Trace from Agilent (Waldbronn, Germany). Ionization by electronic impact occurred at $70 \mathrm{eV}$. All solvents were of pesticide-grade quality. Reference standards of all compounds were obtained from Cambridge Isotope Laboratories (Andover, MA, USA) or Dr. Ehrenstorfer (Augsburg, Germany). The calibration curve was constructed from 0 to $30 \mathrm{ppb}$ and linearity studied between the limit of quantification (LOQ) and $30 \mathrm{ppb}$. Endosulfan-d4 (0.5 ppb) was used as the internal standard. Peak areas were used as the basis for quantification, and the limit of detection (LOD) $(m+3 \sigma)$ and LOO $(\mathrm{m}+10 \sigma)$ were determined after 15 integrations of a blank sample. LOQ was approximately $0.5 \mathrm{ppb}$ for each compound with coefficients of variation of 4.3 to $5.2 \%$. Samples were analyzed in a blind procedure together with controls consisting of samples spiked with 2 or 5 ppb of each compound tested. Since it was previously established that variations in plasma lipids may contribute up to $10 \%$ of the variance of organochlorine serum concentrations, results were corrected for total lipid content calculated by the recommended method (9) after total cholesterol, free cholesterol, phospholipid and triglyceride measurements were conducted using a standard enzymatic procedure on a MEGA chemistry analyzer (MEGA Diagnostics Inc., Los Angeles, CA, USA).

\section{Statistical analysis}

Serum levels of organochlorines corrected for lipid content were expressed as mean $\pm \mathrm{SD}$. When organochlorine results were lower than LOQ, a " 0 " value was recorded and these results were included in all subsequent calculations. The Chi- squared test was used to compare the proportion of smokers and non-smokers and distribution between rural and urban living in the two age-matched groups. Body mass index (BMI, weight $(\mathrm{kg}) /$ height $\left(\mathrm{m}^{2}\right)$ ) and concentrations of $\mathrm{p}, \mathrm{p}^{\prime}$ DDE and HCB of cases and controls were compared using a Mann-Whitney U-test. The same test was performed to assess the relationship in the cancer group between pesticide serum concentration and ER status or metastatic spread to lymph nodes, while association between pesticide level and tumor size or Bloom stage was tested by the Spearman correlation coefficient test. Multiple logistic regression was applied to measure the association between $p, p^{\prime}-D D E$ or HCB serum levels and breast cancer. Results were expressed as odds ratios (OR) and associated 95\% confidence intervals (CI). They were adjusted for available potential confounders: menopausal status, full-term pregnancies, lactation, use of HRT and family history of breast cancer. Calculations were done not only with continuous, but also binary, values $\left(<\mathrm{LOQ}\right.$ or $>$ LOQ) for $\mathrm{p}, \mathrm{p}^{\prime}-\mathrm{DDE}$ and HCB. All results were considered to be significant at the $5 \%$ critical level $(p<0.05)$. Calculations were done using the SAS statistical package (SAS Institute, version 8 for Windows, StatSoft, MaisonAlfort, France).

\section{Results}

Demographic data of the cases and controls are summarized in Table 1. Both groups were similar with respect to smoking $(p=0.56)$, living environment $(p=0.72)$ and BMI $(p=0.41)$. The distribution characteristics of organochlorines in cases and controls are presented in Table 2. The most frequently quantified organochlorine was $p, p^{\prime}-D D E$ (73.5\% of all samples). $0, p^{\prime}$-DDT and $o, p^{\prime}$-DDE were below detection levels. HCB was quantified in $10.6 \%$ of all samples. The mean level of $p, p^{\prime}-D D E$ was significantly higher $(p<0.0001)$ in women with breast cancer than in control subjects $(3.46 \pm 3.48 \mathrm{ppb}(0.58 \pm 0.58 \mu \mathrm{g} / \mathrm{g}$ lipid) vs. $1.85 \pm 2.09$ $\mathrm{ppb}(0.31 \pm 0.35 \mu \mathrm{g} / \mathrm{g}$ lipid)). The same conclusion applied for HCB $(0.66 \pm 1.25 \mathrm{ppb}(0.11 \pm 0.21 \mu \mathrm{g} / \mathrm{g}$ lipid) in patients vs. $0.20 \pm 1.02 \mathrm{ppb}(0.03 \pm 0.17 \mu \mathrm{g} / \mathrm{g}$ lipid) in controls $(p<0.0001)$ ). These results confirm our previous findings on a smaller population (10), even if $\mathrm{HCB}$ was present in a larger proportion of cases $(32 \%)$. Since HCB results considered positive are limited to $11 \%$ of the samples, the results for HCB remain to be confirmed.

For the most abundant residue, a graphical illustration of our results is proposed in Figure 1, after separation of values into tertiles. This clearly illustrates that the proportion of cases compared to controls significantly increased according to tertiles.

The body burden of $p, p^{\prime}-D D E$ and HCB have been measured in relationship to breast cancer risk with consideration of potential confounding factors (Table 3). The association between the presence of $p, p^{\prime}-D D E$ or HCB (negative or positive depending on whether results were below or above LOQ) and breast cancer remained highly significant $(p<0.0001)$. The effects of parity and familial history of breast cancer were not significant, while post-menopausal women appeared to be at higher risk of developing the disease. When expressing $p, p^{\prime}-D D E$ and $H C B$ in terms of continuous 
Table 1 Distribution of breast cancer patients and control women according to selected characteristics.

\begin{tabular}{|c|c|c|c|}
\hline & $\begin{array}{l}\text { Cases } \\
(n=231)\end{array}$ & $\begin{array}{l}\text { Controls } \\
(n=290)\end{array}$ & $\mathrm{p}$-value \\
\hline Age, years & $53.6 \pm 11.4$ & $51.7 \pm 11.9$ & NS \\
\hline $\mathrm{BMI}, \mathrm{kg} / \mathrm{m}^{2}$ & $23.3 \pm 6.7$ & $22.8 \pm 6.9$ & NS \\
\hline Urban living, \% & 47.4 & 47.2 & NS \\
\hline Smoking, \% & 43.3 & 44.9 & NS \\
\hline Age at menarche, years & $13.2 \pm 1.5$ & $12.8 \pm 2.4$ & NS \\
\hline Full-term pregnancies, $\% 0$ & 18.6 & 23.4 & NS \\
\hline 1 & 23.2 & 38.8 & \\
\hline 2 & 30.8 & 22.6 & \\
\hline 3 & 17.8 & 13.8 & \\
\hline 4 & 9.6 & 1.4 & \\
\hline Breast feeding, \%* & 57.8 & 60.4 & NS \\
\hline Menopausal status, \% & 69.3 & 52.8 & $\mathrm{p}<0.05$ \\
\hline Age at menopause, years** & $49.0 \pm 5.7$ & $47.2 \pm 5.6$ & NS \\
\hline $\mathrm{HRT}, \% * *$ & 43.8 & 66.6 & $p<0.05$ \\
\hline Family history of breast cancer, \% & 30.4 & 24.0 & NS \\
\hline
\end{tabular}

*Limited to women who had one or more full-term pregnancies; **limited to post-menopausal women. NS, not significant.

variables, logistic regression analysis revealed that the odds ratios were equal to 1.24 and 1.53 , respectively (see footnote Table 3 ). The significance of other risk factors in the logistic regression did not change.

In the breast cancer group, ER status was available for 128 women but was not correlated with the $p, p^{\prime}-$ DDE level $(p=0.95)$ or the HCB level $(p=0.87)$. The organochlorine level was independent of lymph node presence $\left(n=167, p=0.54\right.$ for $p, p^{\prime}-D D E$ and $p=0.82$ for $\mathrm{HCB}$ ) and Bloom stage ( $n=40$ stage $l, n=63$ stage II and $n=39$ stage III, $p$ from 0.26 to 0.70 for both $p, p^{\prime}$ DDE and HCB). Tumor size was recorded in 153 cases $(18.41 \pm 11.14 \mathrm{~mm})$. No correlation $(p=0.33)$ was found between this parameter and the serum $p, p^{\prime}-$ DDE level, but a significant association $(p=0.026)$ appeared between tumor size and HCB level.

\section{Discussion}

Endogenous or synthetic estrogens are well known breast cancer promoters. Epidemiological studies have shown that breast cancer incidence is increased by a prolonged exposure to estrogens due to early menarche, nulliparity and late menopause (11), whereas premature menopause (12) or prolonged breast-feeding are protective. The most convincing evidence that exogenous estrogens have an impact on the disease came from diethylstilbestrol exposure (13), with increased reproductive cancers in both mothers and daughters. Epidemiological studies of the Nurse Health study indicate that 5-10 years of exposure to estrogens after menopause is associated with a 1.40 (2) or 1.1 (3) or 1.41 (14) increased risk of breast cancer.

The association of DDT, an organochlorine insecticide, with egg fragility and reduced eggshell calcium in birds suggested that endocrine reproductive mechanisms in animals might be altered by pesticides (15). Widespread use of DDT began in the United States in 1946 and increased until 1959. It then declined steadily until it was effectively stopped in 1972 (16). DDT accumulates in the body, mainly in adipose tissue, and has a half-life of 7-10 years (17). DDT and its

Table 2 Distribution of organochlorines in cases and controls.

\begin{tabular}{|c|c|c|c|c|}
\hline Organochlorines & & $\begin{array}{l}\text { Cases } \\
(n=231)\end{array}$ & $\begin{array}{l}\text { Controls } \\
(n=290)\end{array}$ & $\mathrm{p}$-Value \\
\hline \multirow[t]{5}{*}{$p, p^{\prime} D D E$} & $>0.5 \mathrm{ppb}(\%)$ & 76.2 & 71.1 & \\
\hline & $>0.5 \mathrm{ppb}(\mathrm{n})$ & 176 & 206 & \\
\hline & Mean $(p p b) \pm S D$ & $3.46 \pm 3.48$ & $1.85 \pm 2.09$ & $\mathrm{p}<0.0001$ \\
\hline & Mean $(\mu \mathrm{g} / \mathrm{g}$ lipid $) \pm S D$ & $0.58 \pm 0.58$ & $0.31 \pm 0.35$ & $\mathrm{p}<0.0001$ \\
\hline & Range ( $\mu \mathrm{g} / \mathrm{g}$ lipid) & $0-3.24$ & $0-2.07$ & \\
\hline \multirow[t]{5}{*}{$p, p^{\prime} D D T$} & $>0.5 \mathrm{ppb}(\%)$ & 0.4 & 0.7 & \\
\hline & $>0.5 \mathrm{ppb}(\mathrm{n})$ & 1 & 2 & \\
\hline & Mean $(p p b) \pm S D$ & $0.1 \pm 0.5$ & $0.1 \pm 0.2$ & NS \\
\hline & Mean $(\mu \mathrm{g} / \mathrm{g}$ lipid $) \pm S D$ & $0.02 \pm 0.08$ & $0.02 \pm 0.03$ & NS \\
\hline & Range ( $\mu \mathrm{g} / \mathrm{g}$ lipid) & $0-0.67$ & $0-0.47$ & \\
\hline$o, p^{\prime} D D E$ & $0.5 \mathrm{ppb}(\%)$ & 0 & 0 & \\
\hline$o, p^{\prime} D D T$ & $>0.5 \mathrm{ppb}(\%)$ & 0 & 0 & \\
\hline \multirow[t]{5}{*}{ HCB } & $>0.5 \mathrm{ppb}(\%)$ & 12.6 & 8.9 & \\
\hline & $>0.5 \mathrm{ppb}(\mathrm{n})$ & 29 & 26 & \\
\hline & Mean $(p p b) \pm S D$ & $0.66 \pm 1.25$ & $0.20 \pm 1.02$ & $\mathrm{p}<0.0001$ \\
\hline & Mean ( $\mu \mathrm{g} / \mathrm{g}$ lipid) & $0.11 \pm 0.21$ & $0.03 \pm 0.17$ & $\mathrm{p}<0.0001$ \\
\hline & Range ( $\mu \mathrm{g} / \mathrm{g}$ lipid) & $0-1.67$ & $0-0.67$ & \\
\hline
\end{tabular}

NS, not significant. 


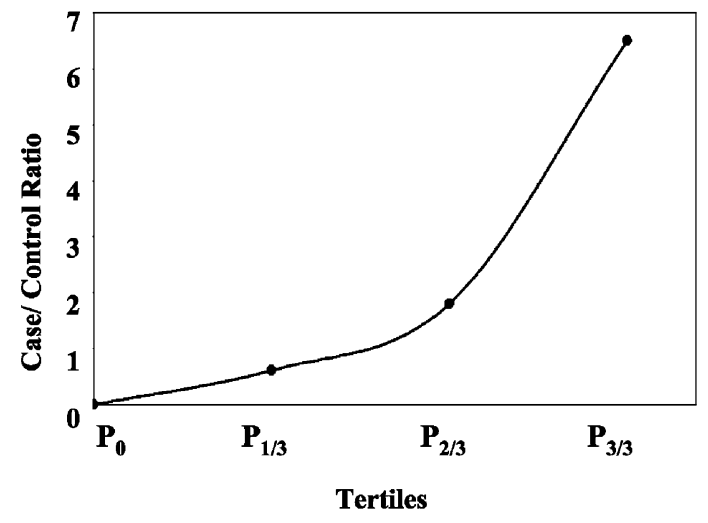

Figure 1 Case/control ratio according to DDE tertiles: the proportion of cases compared to controls (expressed as a ratio) increases according to $p, p^{\prime}-D D E$ serum level. $P$, percentile.

major metabolite, $p, p^{\prime}-D D E$, have been demonstrated to have estrogenic properties not only in vitro but also in vivo $(15,18-20)$. Pesticides, especially organochlorines, have long been proved to induce in experimental animals biological responses comparable to those of endogenous estrogens, such as increased uterine weight and vaginal epithelial cornification (19), and consequently have been called "endocrine disrupters". Experimental studies have shown the promoting activity of organochlorine compounds in the development of estrogen-related tumors in animals $(18,21)$. In humans, the consequences of organochlorine exposure have been mostly evaluated in populations with known or suspected occupational or acute accidental exposure $(20,22)$, but the link between myeloma, leukemia, brain or lung cancer and pesticide exposure is far from being evident. However, the general population is exposed daily to low levels of these environmental compounds through dietary habits, water source and food chain (23). Thus, chronic human exposure to such "endo- crine disrupters" could increase the risk of endocrinesensitive tumors.

Previous studies that have investigated the possible association between blood or fat levels of organochlorines and breast cancer incidence led to controversial findings (for a review, see 6 ). Our results show a significant difference in organochlorine levels between cases and age-matched controls. These observations are in agreement with the first results published by Wolff et al. (24) and Dewailly et al. (7). We had previously demonstrated that $p, p^{\prime}-D D E$ and HCB serum levels were higher in women suffering from breast cancer than in controls (10), but established breast cancer risk factors were not evaluated and could have influenced the results. In the present study, we have increased the study population and recorded as much information as possible to allow multivariate statistical analysis.

Concerning DDT, we do not confirm a positive correlation between the $p, p^{\prime}$-DDE levels and the ER status in the breast cancer group. No increased risk was apparent when familial history of breast tumor was reported. Nulliparous women did not have a higher risk than women with children, and taking into consideration breast-feeding for parous women, conclusions were not altered. Undergoing menopause (with or without HRT) did not modify the results either. The incidence of patients with node positivity was not increased in women considered as exposed to DDT. However, the risk was higher in post-menopausal women. Altogether, our data demonstrate that $p, p^{\prime}-$ DDE and breast cancer are significantly associated regardless of the ER status, the Bloom stage or the metastatic ability through the lymphatic way.

The positive association found between HCB and breast cancer, if confirmed on more patients, reinforces data published about HCB levels in breast adipose tissues $(25,26)$. No correlation between HCB level and ER status, Bloom stage or lymph node metastasis was observed. The association between

Table 3 Multiple logistic regression applied to case and control data for (a) DDE and (b) HCB, respectively, and adjusted for confounding factors.

\begin{tabular}{lccc}
\hline Variables & $\begin{array}{l}\text { Regression coefficient } \\
\pm \text { standard error }\end{array}$ & OR (95\% Cl) & p-Value \\
\hline (a) DDE & & & \\
Intercept & $-1.42 \pm 0.29$ & $2.21(1.41-3.48)$ & 0.0006 \\
DDE* & $0.79 \pm 0.23$ & $1.53(0.89-2.60)$ & 0.12 \\
Parity & $0.42 \pm 0.27$ & $0.63(0.41-1.00)$ & 0.05 \\
Parity $\times$ breast feeding & $0.46 \pm 0.23$ & $3.25(2.06-5.13)$ & $<0.0001$ \\
Menopause & $1.18 \pm 0.23$ & $2.20(1.56-3.25)$ & $<0.0001$ \\
Menopause $\times$ HRT & $1.17 \pm 0.25$ & $1.34(0.89-2.03)$ & 0.16 \\
Familial history of breast cancer & $0.29 \pm 0.21$ & & $<0.0001$ \\
(b) HCB & & & 0.07 \\
Intercept & $-1.15 \pm 0.25$ & $4.99(2.95-8.43)$ & 0.06 \\
HCB** & $1.61 \pm 0.27$ & $1.65(0.95-2.85)$ & $<.66(0.42-1.02)$ \\
Parity & $0.49 \pm 0.28$ & $3.16(1.98-5.05)$ & $<0.0001$ \\
Parity $\times$ breast feeding & $-0.42 \pm 0.23$ & $2.56(1.65-3.69)$ & 0.0001 \\
Menopause & $1.15 \pm 0.24$ & $1.37(0.89-2.10)$ & 0.14 \\
Menopause $\times$ HRT & $1.09 \pm 0.24$ & $0.38 \pm 0.21$ & \\
Familial history of breast cancer & & & \\
\hline
\end{tabular}

*When DDE was expressed as a continuous variable, the regression coefficient was $0.22( \pm 0.04), \mathrm{OR}=1.24(95 \% \mathrm{Cl}: 1.15-$ 1.34), $\mathrm{p}<0.0001$. ${ }^{* *}$ When HCB was expressed as a continuous variable, the regression coefficient was $0.43( \pm 0.11), \mathrm{OR}=1.53$ (95\% Cl: $1.23-1.90), \mathrm{p}<0.0001$. 
HCB presence and breast cancer risk was strengthened after adjustment for menopausal status. In women who experienced at least one full-term pregnancy and after 1 month (or more) of breast-feeding, the observed incidence rate was slightly (but not significantly) decreased. Moreover, women previously exposed to HCB did not exhibit higher grade malignancies, evaluated by the Bloom's classification, nor increased incidence of lymph node metastasis. Finally, the low incidence of metastatic breast disease (1 liver metastasis, 2 bone metastasis) precluded any conclusion concerning the possible involvement of $\mathrm{HCB}$ in promoting metastatic disease.

In conclusion, despite the inclusion of established breast cancer risk factors in our data, whether or not environmental hormonally active agents have a causal role in initiation or promotion of breast cancer is difficult to definitively conclude; but since known risk factors may account for only 50 to $60 \%$ of breast cancer incidence (27), our data - demonstrating a higher frequency of detectable $p, p^{\prime}$-DDE or HCB in the breast cancer population when compared to controls - may at least indicate that exposure to environmental endocrine disrupters is a factor in breast carcinogenesis. It remains to be determined whether or not the association between the organochlorine serum levels and the risk of breast cancer demonstrated here is the consequence of this estrogenic disrupting activity. Since polychlorinated biphenyls and 1,1-dichloro-2,2bis (4-chlorophenyl) ethylene are the most abundant organochlorine pollutants, it is alternatively possible that organochlorine levels reflect the chronic exposure of the population to a large variety of uncharacterized environmental pollutants, some of which are endowed with carcinogenic activity. Prospective studies have to confirm these observations.

\section{References}

1. Hesch RD, Kenemans P. Hormonal prevention of breast cancer: proposal for a change in paradigm. Br J Obst Gyn 1999;106:1006- 18.

2. Schairer C, Byrne C, Keyl P, Brinton LA, Sturgeon SR, Hoover R. Menopausal estrogen and estrogen-progestin replacement therapy and risk of breast cancer. Cancer Causes Control 1994;5:491-500.

3. Ross RK, Paganini-Hill A, Wan PC, Pike MC. Effect of hormone replacement therapy on breast cancer risk: estrogen versus estrogen plus progestin. J Natl Cancer Inst 2000;92:328-32.

4. Writing Group for the Women's Health Initiative Investigators. Risks and benefits of estrogen plus progestin in healthy postmenopausal women: principal results from the Women's Health Initiative randomized controlled trial. J Am Med Assoc 2002;288:321-33.

5. Colditz GA. Relationship between estrogen levels, use of hormone replacement therapy, and breast cancer. J Natl Cancer Inst 1998;90:814-23.

6. Cocco P. On the rumors about the silent spring. Review of the scientific evidence linking occupational and environmental pesticide exposure to endocrine disruption health effects. Cad Saúde Pública 2002;18:379- 402.
7. Dewailly E, Dodin S, Verreault R, Ayotte P, Sauvé L, Morin $\mathrm{J}$, et al. High organochlorine body burden in women with estrogen receptor-positive breast cancer. J Natl Cancer Inst 1994;86:232 - 4 .

8. Charlier C, Plomteux G. Determination of organochlorine pesticide residues in blood of healthy individuals. Clin Chem Lab Med 2002;40:361 - 4.

9. Phillips DL, Pirkle JL, Burse VW, Bernert J, Henderson L, Needham $L$, et al. Chlorinated hydrocarbon levels in human serum: effects of fasting and feeding. Arch Environ Contam Toxicol 1989;18:495-500.

10. Charlier C, Albert A, Herman P, Hamoir E, Gaspard U, Meurisse $M$, et al. Breast cancer and serum level of organochlorine residues. Occup Environ Med 2003;60:348-51.

11. Boyle P. Epidemiology of breast cancer. Bailliere Clin Oncol 1988;2:1-57.

12. MacMahon B, Cole P, Brown J. Etiology of human breast cancer: a review. J Natl Cancer Inst 1973;50:21-42.

13. Greenberg ER, Barrett JA, Resseguie L, Barrett JA, Burnside S, Lanza LL, et al. Breast cancer in mothers given diethylstilbestrol in pregnancy. $\mathrm{N}$ Engl $\mathrm{J}$ Med 1984;132:1059-60.

14. Colditz GA, Hankinson SE, Hunter DJ, Willett WC, Manson JE, Stampfer MJ, et al. The use of estrogens and progestins and the risk of breast cancer in postmenopausal women. N Engl J Med 1995;332:1589-93.

15. Wiemeyer SN, Lamont TG, Bunck CM, Sindelar CR, Gramlich FJ, Fraser JD, et al. Organochlorine pesticide, polychlorobiphenyl and mercury residues in bald eagle eggs (1969-1979) and their relationships to shell thinning and reproduction. Arch Environ Contam Toxicol 1984;13:529-49.

16. Key $\mathrm{T}$, Reeves G. Organochlorines in the environment and breast cancer. Br Med J 1994;308:1520-1.

17. Woodruff T, Wolff MS, Davis DL, Hayward D. Organochlorine exposure estimation in the study of cancer etiology. Environ Res 1994;65:132-44.

18. Robison AK, Sirbasku DA, Stancel GM. DDT supports the growth of an estrogen-responsive tumour. Toxicol Lett 1985;27:109-13.

19. Nelson JA. Effects of dichlorodiphenyltrichloroethane (DDT) analogs and polychlorinated biphenyl (PCB) mixtures on $17 \beta-\left[{ }^{3} \mathrm{H}\right]$ estradiol binding to rate uterine receptor. Biochem Pharmacol 1974;23:447-51.

20. Adami HO, Lipworth L, Titus-Ernstoff L, Hsieh CC, Hanberg A, Ahlborg $U$, et al. Organochlorine compounds and estrogen-related cancers in women. Cancer Causes Control 1995;6:551-66.

21. Scribner JD, Mottet NK. DDT acceleration of mammary gland tumours induced in the male Sprague-Dawley rat by 2-acetamidophenanthrene. Carcinogenesis 1981;2:123-39.

22. Blair A, Grauman DJ, Lubin JH, Fraumeni JF. Lung cancer and other causes of death among licensed pesticide applicators. J Natl Cancer Inst 1983;71:31-7.

23. Travis $C$, Arms AD. The food chain as a source of toxic chemical exposure. In: Lave LB, Upton AC, editors. Toxic chemicals, health and the environment. Baltimore: John Hopkins University Press, 1987:95-123.

24. Wolff MS, Toniolo PG, Lee RW, Rivera M, Dubin N. Blood levels of organochlorine residues and risk of breast cancer. J Natl Cancer Inst 1993;85:648-52.

25. Liljegren G,Hardell L, Lindstrom G, Dahl P, Magnuson A. Case-control study on breast cancer and adipose tissue concentrations of congener specific polychlorinated biphenyls, DDE and hexachlorobenzene. Eur J Cancer Prev 1998;7:135-40.

26. Guttes S, Failing K, Neumann K, Kleinstein J, Georgii S, Brunn $\mathrm{H}$. Chlororganic pesticides and polychlorinated biphenyls in breast tissue of women with benign and 
malignant breast disease. Arch Environ Contam Toxicol 1998;35:140-7.

27. Stanford JL, Weiss NS, Voigt LF, Daling JR, Habel LA, Rossing MA. Combined estrogen and progestin hor- mone replacement therapy in relation to risk of breast cancer in middle-aged women. J Am Med Assoc 1995;274:137-42.

Received May 19, 2003, accepted September 15, 2003 
Copyright of Clinical Chemistry \& Laboratory Medicine is the property of Walter de Gruyter $\mathrm{GmbH} \& \mathrm{Co}$. KG. and its content may not be copied or emailed to multiple sites or posted to a listserv without the copyright holder's express written permission. However, users may print, download, or email articles for individual use. 